\title{
DANOS CAUSADOS POR PERCEVEJO-DE-RENDA NA PRODUÇÃO DE PARTE AÉREA E RAÍZES DE MANDIOCA
}

\section{ECONOMIC DAMAGE CAUSED BY LACEBUG UPON CASSAVA ROOT AND FOLIAGE YIELD}

\author{
Josefino de Freitas FIALHO ${ }^{1}$ \\ Eduardo Alano VIEIRA ${ }^{2}$ \\ Silvana Vieira de PAULA-MORAES ${ }^{3}$ \\ Marilia Santos SILVA ${ }^{4}$ \\ Nilton Tadeu Vilela JUNQUEIRA 5
}

\begin{abstract}
RESUMO
Esta pesquisa avaliou o dano provocado pelo percevejo-de-renda Vatiga illudens (Drake, 1922) (Hemiptera: Tingidae) na produtividade de raízes e da parte aérea em mandioca. Os experimentos foram conduzidos entre 1994 e 1997 na área experimental da Embrapa Cerrados, no município de Planaltina - DF. Utilizou-se o delineamento experimental de blocos ao acaso, com quatro repetições, em esquema de parcelas subdivididas. As parcelas foram constituídas pelas variedades e nas subparcelas, casualizadas dentro de cada bloco, foram testados os tratamentos sem controle e com controle químico do percevejo-de-renda, através de pulverizações quinzenais com inseticidas à base de monocrotofós, dimetoato e vamidotion. Os resultados revelaram que 1) elevados níveis de infestação de ninfas e de adultos do percevejo-de-renda reduziram a produtividade da parte aérea e das raízes em mandioca e 2) pulverizações com inseticidas resultaram em acréscimos de produção de raízes e parte aérea em mandioca.
\end{abstract}

Palavras-chave: Manihot esculenta; Vatiga illudens; pragas de mandioca; Tingidae.

\section{ABSTRACT}

This research evaluated the economic damage of lacebug Vatiga illudens (Drake, 1922) (Hemiptera: Tingidae) upon cassava root and foliage yield. The experiments were carried out from 1994 to 1997 at the experimental area of Embrapa Cerrados, at the municipality of Planaltina - DF. The experimental design used was completely randomized blocks with four replications, in a scheme of subdivided plots. The plots consisted of varieties and in the subplots, randomized within each block, treatments with or without chemical control of lacebug were applied, mediated by sprays every two weeks with insecticides based on monocrotophos, dimetoate and vamidotion. The results obtained revealed that 1) high levels of lacebug nymph and adult infestation reduced cassava foliage and root yield and that 2) the sprays with insecticides resulted in increases of cassava foliage and root yield

Key-words: Manihot esculenta; Vatiga illudens; cassava plagues; Tingidae.

²Engenheiro Agrônomo, Doutor em Fitomelhoramento, Pesquisador da Embrapa Cerrados, Planaltina (DF), Brasil. E-mail: vieiraea@cpac.embrapa.br. ${ }^{3}$ Engenheira Agrônoma, Mestre em Entomologia, Pesquisadora da Embrapa Cerrados, Planaltina (DF), Brasil. E-mail: silvana@cpac.embrapa.br. ${ }^{4}$ Engenheira Agrônoma, Doutora em Biologia Molecular, Pesquisadora da Embrapa Cerrados, Planaltina (DF), Brasil. E-mail: marilia@cpac.embrapa.br.

${ }^{5}$ Engenheiro Agrônomo, Doutor em Fitopatologia, Pesquisador da Embrapa Cerrados, Planaltina (DF), Brasil. E-mail: junqueir@cpac.embrapa.br. 


\section{INTRODUÇÃO}

No Brasil, centro de origem e diversidade da mandioca (Manihot esculenta Crantz) (Olsen, 2004), a espécie é cultivada em todas as regiões (Costa et al., 2003), ocupando papel de destaque na indústria, alimentação humana e animal (ElSharkawy, 2003). Atualmente o Brasil é o segundo maior produtor mundial da cultura, sendo responsável por cerca de $15 \%$ do total produzido no mundo (FAO, 2007). A cultura exerce papel destacado na alimentação humana no continente Sul Americano e Africano, por ser a principal fonte de carboidratos (Mühlen et al., 2000; El-Sharkawy, 2003).

O Cerrado brasileiro, que ocupa $24 \%$ do território nacional, apesar de ser um dos principais centros de dispersão da mandioca e apresentar características de clima e solo que o colocam como uma das regiões mais propícias para o cultivo de mandioca no país, é responsável por apenas $10 \%$ da produção nacional, com produtividade média de $11 \mathrm{t} \mathrm{ha}^{-1}$, a qual é inferior à média nacional de $12 \mathrm{t}$ ha $^{-1}$ (Souza \& Fialho, 2003). A baixa produtividade nessa região decorre da não utilização de variedades melhoradas e indicadas pela pesquisa e da ocorrência de pragas e doenças (Souza \& Fialho, 2003). Como o ciclo da mandioca é relativamente longo (de 10 a 24 meses), a cultura está sujeita a um grande número de fatores bióticos (pragas e doenças) e abióticos (seca, alumínio tóxico no solo, calor, salinidade, etc) capazes de comprometerem a produtividade final (El-Sharkawy, 2003).

Estima-se que cerca de 200 espécies de artrópodes causem injúrias a cultivos de mandioca na América. Entretanto, ainda existem lacunas no conhecimento que caracterizem o impacto na produtividade da cultura da mandioca (Bellotti et al., 1999). No Cerrado do Brasil Central, o percevejode-renda, Vatiga illudens (Drake, 1922) (Hemiptera: Tingidae), constitui-se em uma praga de ocorrência freqüente na cultura, principalmente na época seca (Farias, 1987). Os adultos do inseto apresentam coloração cinza e medem, aproximadamente, três milímetros de comprimento, enquanto suas ninfas são brancas e menores que os adultos. Ninfas e adultos, primeiramente atacam face inferior das folhas da parte basal da planta, para sugam a seiva no floema da planta, e posteriormente, em ataques severos, chegam até às folhas apicais (Farias, 1987). Ataques desse inseto provocam pontuações cloróticas nas folhas de coloração amarelabronzeada, comprometendo a área fotossintética da planta (Farias, 1987).

A praga infesta à cultura no início da estação seca e pode reduzir a produtividade da lavoura quando da ausência de um microclima úmido, de cultivares resistentes ou de métodos efetivos para o controle da praga. Entretanto, da mesma forma que ainda não foi determinada à redução de produtividade em função do ataque do percevejode-renda, não existem medidas de controle propostas com eficiência para controle da praga
(Ceballos et al., 2004), haja vista que atualmente não existem inseticidas registrados no Ministério de Agricultura, Pecuária e Abastecimento (MAPA) para o controle do percevejo-de-renda na cultura da mandioca.

O objetivo do trabalho foi avaliar o dano provocado pelo percevejo-de-renda na produtividade de raízes e parte aérea de mandioca.

\section{MATERIALE MÉTODOS}

Os experimentos foram conduzidos entre 1994 e 1997, sempre com os plantios na segunda quinzena de outubro, em área experimental da Embrapa Cerrados, situada a $15^{\circ} 35^{\prime} 30^{\prime \prime}$ de latitude sul, 47042'30" de longitude oeste e a uma altitude de 1000 m, no município de Planaltina - DF. Nesta pesquisa foram utilizadas quatro variedades de mandioca com potencial para o cultivo no Cerrado, sendo duas de mesa (Mantiqueira e Jaçanã) e duas para a indústria (IAC 12.829 e EAB 670) (Pereira et al., 1990).

Utilizou-se na pesquisa o delineamento experimental de blocos ao acaso, com quatro repetições, em esquema de parcelas subdivididas. As parcelas foram constituídas pelas variedades e nas subparcelas, casualizadas dentro de cada bloco, foram aplicados os tratamentos sem controle e com controle químico do percevejo-de-renda, por meio de pulverizações quinzenais à base de monocrotofós (200 $\left.\mathrm{g} \mathrm{ha}^{-1}\right)$, dimetoato $\left(200 \mathrm{~g} \mathrm{ha}^{-1}\right) \mathrm{e}$ vamidotion ( $\left.250 \mathrm{~g} \mathrm{ha}^{-1}\right)$, em rodízio quinzenal. Durante as pulverizações as subparcelas tratadas foram protegidas com "paneiro", objetivando evitar a contaminação com inseticidas das subparcelas sem pulverização, permitindo a infestação natural da praga. Cada parcela foi composta por 4 linhas com 20 plantas em espaçamento de $1,00 \mathrm{~m}$ entre linhas e $0,60 \mathrm{~m}$ entre plantas. Cada subparcela foi composta por 4 linhas, com 10 plantas e teve como área útil as 16 plantas centrais. A seleção do material para o plantio bem como os tratos culturais seguiram as recomendações de Pereira et al. (1990).

A infestação da praga foi avaliada, quinzenalmente, durante todo o ciclo da cultura e consistiu na contagem do número de ninfas e adultos do inseto, em uma folha amostrada de cinco plantas previamente marcadas na área útil de cada subparcela. Doze meses após o plantio foram colhidas as 16 plantas centrais de cada subparcela (área útil) e mensurados os caracteres produtividade de raízes em $\mathrm{kg} \mathrm{ha}^{-1}(\mathrm{PR})$, a partir da pesagem das raízes de todas as plantas da área útil da parcela $\mathrm{e}$ produtividade da parte aérea em $\mathrm{kg} \mathrm{ha}^{-1}$ (PPA), por meio da pesagem da massa verde da parte aérea das plantas, a partir de corte realizado a $10 \mathrm{~cm}$ do solo. Posteriormente, foi estimado o ganho de produtividade em \% (GP), por meio da razão entre a produtividade média de raízes e de parte aérea em cada ano, com e sem pulverização e posterior multiplicação por 100. Após as avaliações o material vegetal foi destruído por ainda não ter sido 
estabelecido os níveis de resíduos para os agrotóxicos utilizados na pesquisa.

Os dados coletados foram submetidos à análise de variância, em esquema de parcelas subdivididas, e as médias foram comparadas pelo teste de Tukey a $5 \%$ de probabilidade. Posteriormente, estimou-se a correlação de Pearson ( $r$ ) entre o número de ninfas e adultos de percevejo-de-renda nas folhas de mandioca com a produtividade de parte aérea em $\mathrm{kg} \mathrm{ha}^{-1}$ (PPA) e a produtividade de raízes em $\mathrm{kg} \mathrm{ha}^{-1}(\mathrm{PR})$, entre os anos de 1994 e 1997. A significância dos coeficientes de correlação foi estimada por meio do teste t. Para a realização das análises estatísticas foi utilizado o programa SANEST (Zonta \& Machado, 1984).

\section{RESULTADOS E DISCUSSÃO}

Foram detectadas diferenças significativas entre as variedades para os caracteres produtividade de raízes (PR) e a produtividade de parte área (PPA) o que revela a existência de diferenças fenotípicas entre as variedades avaliadas. A presença de elevada variabilidade era esperada, uma vez que foram avaliadas variedades desenvolvidas para mesa (consumo na alimentação humana) e indústria (produção de farinha e fécula). Não foram detectadas diferenças significativas entre os anos para os caracteres PR e PPA e apenas para o caráter PR houve interação significativa entre os fatores anos $\mathrm{e}$ variedades, revelando que a ordem de classificação dos genótipos ao longo dos anos não se manteve constante para o caráter PR. Resultados semelhantes de interação significativa entre os fatores anos e variedades de mandioca para PR foram relatados por Vidigal Filho et al. (2000); Borges et al. (2002). Os coeficientes de variação foram baixos (entre $6,53 \%$ e 13,44\%), revelando uma elevada precisão experimental.

A pulverização com inseticidas fosforados influenciou, significativamente, a PR e PPA, e apresentou interação significativa com o fator ano para os dois caracteres aferidos, indicando que o reflexo da pulverização com inseticidas no rendimento da cultura não é constante ao longo dos anos. Nos anos de 1994, 1996 e 1997 houve diferenças significativas entre as médias de PR e PPA entre os tratamentos com e sem inseticidas, sendo que em todos esses anos o tratamento sem inseticida provocou decréscimo na produtividade da cultura (Tabela 1). As maiores quedas de PR e PPA, em razão da não aplicação de inseticida, foram detectadas no ano de 1996 e foram da ordem de $55 \%$ e $48 \%$, respectivamente (Tabela 1 ). Esta situação ocorreu provavelmente em razão do ataque do percevejo-de-renda, uma vez que nesse ano foram observadas as maiores densidades populacionais de ninfas e adultos de percevejosde-renda sobre todas as variedades de mandioca avaliadas, tanto com pulverização como sem pulverização (Tabela 2). Nos anos de 1994 e 1997, as perdas de PR e PPA também foram significativas e elevadas variando de $18 \%$ a $35 \%$ (Tabela 1 ).

TABELA 1 - Comparação de médias dentro dos anos (1994 a 1997) dos caracteres produtividade de parte aérea (PPA) e produtividade de raízes (PR) de quatro variedades de mandioca, colhidas aos 12 meses de idade em Planaltina-DF, considerando os fatores com e sem pulverização com inseticida e ganho de produtividade (GP) em razão da aplicação de inseticida.

\begin{tabular}{llcccc}
\hline \multirow{2}{*}{ Ano } & \multirow{2}{*}{ Tratamento } & \multicolumn{2}{c}{$\mathrm{PPA}$} & \multicolumn{2}{c}{$\mathrm{PR}$} \\
\cline { 2 - 6 } 1994 & Com inseticida & $15053 \mathrm{~A}$ & $\mathrm{~kg} \mathrm{ha}$ & & $\mathrm{GP}(\%)$ \\
\multirow{2}{*}{1995} & Sem inseticida & $11783 \mathrm{~B}$ & 100 & $17069 \mathrm{~A}$ & 130 \\
& Com inseticida & $19845 \mathrm{~A}$ & 110 & $20607 \mathrm{~A}$ & 100 \\
\multirow{2}{*}{1996} & Sem inseticida & $18987 \mathrm{~A}$ & 100 & $19845 \mathrm{~A}$ & 100 \\
\multirow{2}{*}{1997} & Com inseticida & $17336 \mathrm{~A}$ & 148 & $19348 \mathrm{~A}$ & 155 \\
& Sem inseticida & $11737 \mathrm{~B}$ & 100 & $12492 \mathrm{~B}$ & 100 \\
\multirow{2}{*}{ Média Geral } & Com inseticida & $16333 \mathrm{~A}$ & 135 & $22538 \mathrm{~A}$ & 118 \\
& Sem inseticida & $12121 \mathrm{~B}$ & 100 & $19061 \mathrm{~B}$ & 100 \\
\hline
\end{tabular}

Para cada caráter em cada ano, médias seguidas pela mesma letra, não diferem entre si segundo o teste de Tukey a $5 \%$ de probabilidade. DMS = PPA $\left(1449 \mathrm{~kg} \mathrm{ha}^{-1}\right)$ e PR $\left(1270 \mathrm{~kg} \mathrm{ha}^{-1}\right)$.

TABELA 2 - Número médio de ninfas (NN) e adultos (NA) de percevejo-de-renda, em quatro variedades de mandioca sem pulverização com inseticidas, no período de 1994 a 1997 em Planaltina-DF.

\begin{tabular}{|c|c|c|c|c|c|c|c|c|}
\hline \multirow[b]{2}{*}{ Ano } & \multicolumn{4}{|c|}{ Número de ninfas } & \multicolumn{4}{|c|}{ Número de adultos } \\
\hline & Mantiqueira & Jaçanã & $\begin{array}{r}\text { EAB } \\
670\end{array}$ & $\begin{array}{c}\text { IAC } \\
12829\end{array}$ & Mantiqueira & Jaçanã & $\begin{array}{r}\text { EAB } \\
670\end{array}$ & $\begin{array}{c}\text { IAC } \\
12829\end{array}$ \\
\hline 1994 & 10,48 & 3,81 & 6,18 & 3,21 & 5,15 & 1,98 & 2,64 & 1,92 \\
\hline 1995 & 2,66 & 1,99 & 0,81 & 0,97 & 0,64 & 0,55 & 0,19 & 0,18 \\
\hline 1996 & 39,78 & 22,84 & 17,22 & 13,58 & 8,95 & 5,48 & 4,92 & 3,94 \\
\hline 1997 & 4,62 & 2,84 & 1,99 & 1,97 & 1,90 & 0,90 & 0,68 & 0,91 \\
\hline Média & $14,39 \mathrm{~A}$ & $7,87 \mathrm{~B}$ & 6,55 & $4,93 \mathrm{~B}$ & $4,16 \mathrm{~A}$ & $2,23 \mathrm{~B}$ & $2,11 \mathrm{~B}$ & $1,74 \mathrm{~B}$ \\
\hline
\end{tabular}

Para número de ninfas e adultos, médias seguidas pela mesma letra, não diferem entre si segundo o teste de Tukey a $5 \%$ de probabilidade. DMS = NN $(4)$ e NA $(1,6)$. 
Não houve diferenças significativas entre as médias de PR e PPA, nas condições com e sem aplicação de inseticida, no ano de 1995 (Tabela 1). Nesse ano, foram detectados os menores números de ninfas e adultos de percevejos-de-renda em todas as variedades de mandioca avaliadas, nas condições com e sem pulverização (Tabela 2). Provavelmente, este fato tenha ocorrido em razão do ano de 1995 ter sido desfavorável à ocorrência da praga em razão dos índices de precipitação nos meses de maior incidência natural do inseto (abril, maio e junho), com valores superiores aos outros anos do estudo (dados estação meteorológica da Embrapa Cerrados).

A utilização de inseticidas resultou em incremento da produção de raízes e de parte aérea, evidenciando o efeito nocivo de populações elevadas de percevejo-de-renda sobre a cultura da mandioca. Constata-se, portanto, a necessidade de estudos para se determinar o nível de dano econômico do inseto e ação de princípios ativos de inseticidas para controle do percevejo-de-renda na cultura da mandioca, de forma que esta utilização seja feita de forma racional e integrada com monitoramento das populações em campo para tomada de decisão. Apesar da utilização de inseticidas na cultura para controle de percevejo-de-renda ser proibitivo, em função do longo ciclo da cultura e baixa rentabilidade da produção, diante dos avanços e profissionalização da cadeia produtiva e exploração em grande escala da cultura da mandioca, poderá ocorrer à demanda da minimização de fatores de perdas, como é o caso do percevejo-de-renda. Tais estudos devem contemplar as disposições legais estabelecidas recentemente para testes de agrotóxicos, de forma que outras moléculas inseticidas sejam testadas, especialmente, de grupos químicos seletivos a praga em questão.

Os coeficientes de correlação o número de ninfas e de adultos e a produtividade de raízes e de parte área, nos anos de 1994, 1996 e 1997 foram significativos, negativos e de elevada magnitude, evidenciando que nesses anos tanto o número de ninfas quanto o de adultos, estiveram altamente relacionados com a diminuição da produtividade de raízes e de parte aérea (Tabela 3 ).

TABELA 3 - Coeficiente de correlação de Pearson entre o número de ninfas e de adultos de percevejo-de-renda em folhas de mandioca e os caracteres produtividade de parte aérea em $\mathrm{kg} \mathrm{ha}^{-1}$ (PPA) e produtividade de raízes em $\mathrm{kg} \mathrm{ha}^{-1}(\mathrm{PR})$, em quatro variedades de mandioca colhidas os 12 meses de idade nas condições com e sem pulverização com inseticidas entre os anos de 1994 e 1997 em Planaltina-DF.

\begin{tabular}{cllll}
\hline \multirow{2}{*}{ Ano } & \multicolumn{2}{c}{ PPA } & \multicolumn{2}{c}{ PR } \\
\cline { 2 - 5 } & ninfas & adultos & $-0,87^{*}$ & Adultos \\
\hline 1994 & $-0,93^{*}$ & $-0,90^{*}$ & $-0,89^{*}$ \\
1995 & $-0,21$ & $-0,14$ & $-0,90$ & $-0,52$ \\
1996 & $-094^{*}$ & $-0,91^{*}$ & $-0,92^{*}$ \\
1997 & $-0,92^{*}$ & $-0,88^{*}$ & $-0,78^{*}$ & $-0,82^{*}$ \\
\hline
\end{tabular}

(") significativo a $5 \%$ de probabilidade de erro pelo teste $t$.

A diminuição de produtividade em razão do aumento no número de insetos (ninfas e adultos) pode ter ocorrido pelos danos que o inseto causa às folhas pela sucção, fazendo com que a planta acumule menos fotoassimilados em razão da diminuição da área foliar fotossinteticamente ativa e de despender energia (fotoassimilados) na recomposição das folhas que caíram em função do ataque do inseto (Farias, 1987). Além do que, a queda na produtividade pode ter por base o fato da injúria do percevejo-de-renda desencadear a senescência e perda de folhas, o que ocasiona um comprometimento na área foliar e de nutrição da planta, ainda mais se considerarmos que a mandioca para se adaptar à ausência ou distribuição irregular de precipitação, desenvolveu estratégias em nível foliar de redução da evapotranspiração (fechamento de estômatos e mudança de posição das folhas para menor interceptação de radiação solar) (Alves \& Setter, 2004), que pode ser prejudicada pela queda das folhas. Essa hipótese é corroborada por Santos et al. (2004), que relataram a existência de correlação negativa e significativa entre a severidade da mancha parda da folha da mandioca (Cercosporidium henningsii) que compromete a área foliar da planta, e a produtividade de raízes.

Não foi observada correlação significativa entre as populações de inseto e a produtividade de raízes e parte área no ano de 1995 (Tabela 3). Entretanto, nesse ano as correlações estimadas foram negativas, evidenciando, ao menos, uma tendência de diminuição na produtividade em razão da presença do inseto e que, apesar de não significativas, as correlações com a produtividade de raízes foram relativamente elevadas, com valores de $-0,60$ para número de ninfas e de $-0,52$ para número de adultos (Tabela 3 ). Este fato ocorreu provavelmente em razão do ano ter sido ambientalmente desfavorável à praga, com índices de precipitação superiores aos demais anos do estudo nos meses de maior incidência do inseto (dados estação meteorológica da Embrapa Cerrados).

A variedade mais atacada pelo percevejode-renda foi a cultivar de mesa Mantiqueira (Tabela 2). Cosenza et al. (1981) sugeriram que as diferenças de ataque de percevejo-de-renda entre cultivares estariam relacionadas aos teores de compostos cianogênicos nas plantas. A hipótese da presença de ácido cianídrico $(\mathrm{HCN})$ nas folhas, caule e raízes da planta de mandioca (Cooke \& Coursey, 
1981) como fator de defesa da planta ao ataque de doenças e pragas pode vir a ser um parâmetro a ser considerado, quando do trabalho de seleção de possíveis genótipos resistentes e estudos do mecanismo de resistência por antibiose para o percevejo-de-renda. Uma vez que apesar de Bellotti \& Riis (1994) não terem comprovado a preferência ou fatores adversos na biologia de mandarová-damandioca (Erinnyis ello (Linné, 1758) (Lepidoptera: Sphingidae) e para o ácaro (Mononychellus tanajoa (Bondar, 1938) (Acarina: Tetranychidae) em função da presença de $\mathrm{HCN}$, foi observado sua influência na resistência de genótipos de mandioca as espécies Zonocerus variegatus (Linnaeus) (Orthoptera: Acrididae) e Cyrtomenus bergi (Froeschner) (Hemiptera: Cydnidae) (Bernays et al., 1977; Riis, 1997). Entretanto, os resultados obtidos no presente trabalho, que evidenciaram uma menor infestação da praga nas variedades para indústria, apontam no sentido de que para a comprovação ou não dessa hipótese, devem ser realizados estudos a respeito da correlação entre o teor cianogênico em raízes e folhas de mandioca e o ataque pelo percevejo-de-renda.

Considerando as características

socioeconômicas dos agricultores que exploram a mandiocultura, estudos relacionados à resistência varietal devem ser focados em um programa de melhoramento por ser considerado a medida mais adequada para o controle do percevejo-de-renda (Ceballos et al., 2004). Este programa deve disponibilizar cultivares que minimizem os danos do ataque da praga ou mesmo a desfavoreçam, em função do mecanismo de resistência envolvido. Deve-se considerar, também, que essa medida de controle demanda menos nível tecnológico do agricultor e é menos influenciada pela inabilidade na sua aplicação (Ceballos et al., 2004).

\section{CONCLUSÕES}

Altas infestações de ninfas e de adultos do percevejo-de-renda reduziram a produtividade da parte aérea e das raízes em mandioca;

Pulverizações com inseticida organofosforados resultaram em acréscimos de produção de raízes e parte aérea em mandioca, em função de reduzirem a população da praga.

\section{REFERÊNCIAS}

1. ALVES, A. A. C.; SETTER, T. L. Response of cassava leaf area expansion to water deficit: cell proliferation, cell expansion and delayed development. Annals of Botany, v. 94, n. 4, p. 605-613, 2004.

2. BELLOTTI, A. C.; RIIS, L. Cassava cyanogenic potential and resistance to pests and diseases. Acta Horticulturae, v. 375 , n. 1 , p. $141-151,1994$.

3. BELLOTTI, A. C.; SMITH, L.; LAPOINTE, S. L. Recent advances in cassava pest management. Annual Review of Entomology, v. 44, n. 1, p. 343-370, 1999.

4. BERNAYS, E. A. et al. The relationship of Zonocerus variegatus (L.) (Acridoidea: Pyrgomorphidae) with cassava (Manihot esculenta). Bulletin of Entomological Research, v. 67, n. 3, p. 391-404, 1977.

5. BORGES, M. F.; FUKUDA, W. M. G.; ROSSETTI, A. G. Avaliação de variedades de mandioca para consumo humano. Pesquisa Agropecuária Brasileira, v. 37, n. 11, p. 1559-1565, 2002.

6. CEBALLOS, $\mathrm{H}$. et al. Cassava breeding: opportunities and challenges. Plant Molecular Biology, v. 56, n.4, p. 503-516, 2004.

7. COOKE, R. D; COURSEY, D. G. Cassava: a major cyanide containing food crop. In: VENNESLAND, B. et al. (Ed.). Cyanide in Biology. London: London Academic, 1981. p. 93-114.

8. COSENZA, G. W.; GERIM, S.; COSTA, I. R. S. Resistência de variedade de mandioca ao percevejo-de-renda Vatiga illudens (Drake, 1922). Planaltina: Embrapa Cerrados, 1981. 6 p.

9. COSTA, M. R.; CARDOSO, E. R.; OHAZE, M. M. M. Similaridade genética de cultivares de mandioca (Manihot esculenta) por meio de marcadores RAPD. Ciência e Agrotecnologia, v. 27, n. 1, p. 158-164, 2003.

10. EL-SHARKAWY, M. A. Cassava biology and physiology. Plant Molecular Biology, v. 53, n. 5, p. 621-641, 2003.

11. FOOD AND AGRICULTURE ORGANIZATION OF THE UNITED NATIONS (FAO). FAOSTAT. Disponível em: <http:/l faostat.fao.org/site/567/DesktopDefault.aspx?PagelD=567\#ancor>. Acesso em: 20 fev. 2007.

12. FARIAS, A. R. N. Biologia de Vatiga illudens (Drake, 1922) (Hemíptera: Tingidae) em laboratório. Revista Brasileira de Mandioca, v. 8, n. 1, p. 79-81, 1987.

13. MÜHLEN, G. S.; MARTINS, P. S.; ANDO, A. Variabilidade genética de etnovariedades de mandioca, avaliada por marcadores de DNA. Scientia Agricola, v. 57, n. 2, p. 319-328, 2000.

14. OLSEN, K. M. SNPs, SSRs and inferences on cassava's origin. Plant Molecular Biology, v. 56, n. 4, p. 517-526, 2004.

15. PEREIRA, A. V.; OLIVEIRA, M. A. S.; NASSER, L. C. B. Cultivo da mandioca na região dos cerrados. Brasília: Embrapa Cerrados, 1990. $14 \mathrm{p}$.

16. RIIS, L. Behaviour and population growth of the burrower bug, Cyrtomenus bergi Froeschner: effects of host plants and abiotic factors. 1997. $167 \mathrm{f}$. Tese (Doutorado em Veterinária e Agricultura), Department of Ecology and Molecular Biology, Royal Veterinary and Agricultural University, Copenhagen, 1997.

17. SANTOS, R. P. et al. Avaliação de cultivares de mandioca, para consumo in natura, quanto à resistência à mancha parda da folha. Horticultura Brasileira, v. 22, n. 2, p. 232-237, 2004.

18. SOUZA, L. S.; FIALHO, J. F. Sistema de produção de mandioca para a região do Cerrado. Cruz da Almas: Embrapa Mandioca e Fruticultura Tropical, 2003. 61 p.

19. VIDIGAL FILHO, P. S. et al. Avaliação de cultivares de mandioca na região noroeste do Paraná. Bragantia, v. 59, n. 1, p. 69-75, 2000.

20. ZONTA, E. P.; MACHADO, A. A. SANEST: programa de análise estatística para microcomputadores. UFPel: Pelotas, 1984. 
